\title{
The effect of obesity on regadenoson-induced myocardial hyperemia: a quantitative magnetic resonance imaging study
}

\author{
Edward V. R. DiBella • Jacob U. Fluckiger · Liyong Chen · Tae Ho Kim • \\ Nathan A. Pack • Brian Matthews • Ganesh Adluru • Tiffany Priester • \\ Suman Kuppahally $\cdot$ Ronny Jiji $\cdot$ Chris McGann $\cdot$ Sheldon E. Litwin
}

Received: 7 July 2011/ Accepted: 17 September 2011/Published online: 4 October 2011

(C) The Author(s) 2011. This article is published with open access at Springerlink.com

\begin{abstract}
The $\mathrm{A} 2{ }_{\mathrm{A}}$ receptor agonist, regadenoson, is increasingly used as a vasodilator during nuclear myocardial perfusion imaging. Regadenoson is administered as a single, fixed dose. Given the frequency of obesity in patients with symptoms of heart disease, it is important to know whether the fixed dose of regadenoson produces maximal coronary hyperemia in subjects of widely varying body size. Thirty subjects (12 female, 18 male, mean BMI $30.3 \pm 6.5$, range 19.6-46.6) were imaged on a $3 \mathrm{~T}$ magnetic resonance scanner. Imaging with a saturation recovery radial turboFLASH sequence was done first at rest, then during adenosine infusion $(140 \mu \mathrm{g} /$ $\mathrm{kg} / \mathrm{min})$ and $30 \mathrm{~min}$ later with regadenoson $(0.4 \mathrm{mg} /$ $5 \mathrm{ml}$ bolus). A $5 \mathrm{cc} / \mathrm{s}$ injection of Gd-BOPTA was used for each perfusion sequence, with doses of 0.02 ,
\end{abstract}

Registered at Clinicaltrials.gov NCT00859833.

E. V. R. DiBella · J. U. Fluckiger · L. Chen ·

N. A. Pack - B. Matthews - G. Adluru ·

C. McGann · S. E. Litwin

UCAIR, Department of Radiology, University of Utah,

Salt Lake City, UT, USA

E. V. R. DiBella · J. U. Fluckiger - L. Chen · N. A. Pack Department of Bioengineering, University of Utah,

Salt Lake City, UT, USA

\section{T. H. Kim}

Radiation Physics Laboratory, Sydney Medical SchoolCentral, The University of Sydney, Sydney, NSW,

Australia
0.03 and $0.03 \mathrm{mmol} / \mathrm{kg}$, respectively. Analysis of the upslope of myocardial time-intensity curves and quantitative processing to obtain myocardial perfusion reserve (MPR) values were performed for each vasodilator. The tissue upslopes for adenosine and regadenoson matched closely $(\mathrm{y}=1.1 \mathrm{x}+0.03$, $\mathrm{r}=0.9$ ). Mean MPR was $2.3 \pm 0.6$ for adenosine and $2.4 \pm 0.9$ for regadenoson $(p=0.14)$. There was good agreement between MPR measured with adenosine and regadenoson $(\mathrm{y}=1.1 \mathrm{x}-0.06, \mathrm{r}=0.7)$. The MPR values measured with both agents tended to be lower as BMI increased. There were no complications during administration of either agent. Regadenoson produced fewer side effects. Fixed dose regadenoson and weight adjusted adenosine produce similar measures of MPR in patients with a wide range of body sizes. Regadenoson is a potentially useful vasodilator for stress MRI studies.

\footnotetext{
T. Priester · S. Kuppahally · R. Jiji · C. McGann •

S. E. Litwin

Division of Cardiology, University of Utah,

Salt Lake City, UT, USA

S. E. Litwin

Salt Lake City Veterans Affairs Medical Center, Salt Lake City, UT, USA

S. E. Litwin $(\bowtie)$

Section of Cardiology, Georgia Health Sciences University, 1120 15th St, BBR 6513b, Augusta, GA 30912, USA

e-mail: slitwin@georgiahealth.edu
} 
Keywords Obesity · Myocardial perfusion . Magnetic resonance imaging · Vasodilator . Regadenoson $\cdot$ Adenosine $\cdot$ Coronary

\section{Introduction}

Almost $70 \%$ of people in most developed countries are overweight or obese. Obesity is a risk factor for early and accelerated atherosclerotic cardiovascular disease $[1,2]$. Noninvasive imaging techniques that are capable of detecting obstructive coronary artery disease (CAD) with good sensitivity and specificity in obese patients are increasingly needed. Regadenoson (Lexiscan $^{\mathrm{TM}}$, Astellas Pharma or Rapiscan ${ }^{\mathrm{TM}}$, Rapidscan Pharma Solutions in Europe) is an FDA-approved coronary vasodilator that is a more specific $\mathrm{A} 2 \mathrm{~A}$ receptor agonist than adenosine. Regadenoson has been studied in large trials of single photon emission computed tomography (SPECT) [3-7] and has been used for clinical imaging in over 3 million patients to date. Regadenoson has reduced side effects compared to adenosine. Lack of the need for any dose calculations or pump delivery make regadenoson easier to use. The ability of a single fixed size dose of regadenoson to produce full coronary hyperemia in patients of widely varying body size or adiposity has not been tested extensively with quantitative techniques.

The accuracy of perfusion magnetic resonance imaging (MRI) is comparable or better than stress echocardiography and SPECT approaches in the diagnosis of obstructive CAD [8, 9]. Cardiac MRI is somewhat less susceptible to poor image quality in the setting of obesity compared to ultrasound or SPECT approaches. MRI has the advantages of offering more comprehensive evaluation of cardiac structure and function than SPECT and higher spatial resolution than either of the other techniques. Myocardial perfusion assessment with MRI has mainly been performed using weight-adjusted infusion of adenosine to produce coronary vasodilation at the time of first pass gadolinium imaging. Because adenosine and gadolinium have to be given simultaneously, two separate intravenous access sites are required. In addition, the need to calculate adenosine dose introduces potential for errors. Lastly, a special infusion pump that is compatible with the strong magnetic field is required for the administration of adenosine during MRI.
Injection of a fixed dose of $0.4 \mathrm{mg}$ regadenoson has been shown in a large study to be "not inferior" to adenosine for detection of CAD with SPECT [10, 11]. Additionally, regadenoson was reported to have fewer side effects and to be more tolerable to patients [11]. Regadenoson appears to have advantages in patients with pulmonary disease [12] and asthma [13] and may be less affected by recent caffeine consumption [14]. Regadenoson is very attractive for use during MRI perfusion imaging because a continuous infusion is not required and the coronary hyperemic response occurs rapidly. Thus, the use of regadenoson would obviate the need for a 2nd intravenous access and for a specialized infusion pump. This study was done to: (1) evaluate the use of regadenoson as a coronary vasodilator during perfusion MRI, and (2) to determine whether fixed-dose regadenoson produces comparable coronary hyperemia to weight-dosed adenosine in patients with a wide range of body sizes.

\section{Methods}

Thirty volunteer subjects (12 female, 18 male) of varying weight were recruited. Table 1 lists the characteristics of the subjects. Twenty five $\%$ had one or more known coronary risk factors. All of the subjects gave written informed consent. The study was approved by the institutional review board at the University of Utah. The study is registered at clinicaltrials.gov (\# NCT00859833). Subjects were requested to abstain from food and drinks containing caffeine for $24 \mathrm{~h}$ prior to the study.

\section{MRI protocol}

The subjects were imaged on a 3-Tesla magnet (Siemens Medical Solutions, Erlangen, Germany, Trio or Verio systems) using a 12-element phased array coil. Intravenous access was established in each arm, ECG leads were positioned, the coil array was placed over the chest, and subjects were positioned in the scanner. Dynamic contrast-enhanced myocardial perfusion imaging was done first at rest, then during adenosine infusion $(140 \mu \mathrm{g} / \mathrm{kg} / \mathrm{min})$ and $34 \pm 4 \mathrm{~min}$ later with regadenoson injection $(0.4 \mathrm{mg} / 5 \mathrm{ml}$ followed by a $10 \mathrm{cc}$ saline flush). A timeline is shown in Fig. 1. Adenosine was given first because it has a much shorter duration of action and it was necessary to 
Table 1 Characteristics of study population

\begin{tabular}{|c|c|c|c|}
\hline & $\begin{array}{l}\text { All subjects } \\
\mathrm{n}=28\end{array}$ & $\begin{array}{l}\text { Nonobese } \\
(\mathrm{BMI} \leq 30 \\
\left.\mathrm{kg} / \mathrm{m}^{2}\right) \\
\mathrm{n}=16\end{array}$ & $\begin{array}{l}\text { Obese } \\
(\mathrm{BMI}>30 \\
\left.\mathrm{kg} / \mathrm{m}^{2}\right) \\
\mathrm{n}=12\end{array}$ \\
\hline Male $(\mathrm{n} / \%)$ & $16(57 \%)$ & $8(50 \%)$ & $8(67 \%)$ \\
\hline Female $(\mathrm{n} / \%)$ & $12(43 \%)$ & $8(50 \%)$ & $4(33 \%)$ \\
\hline Smoking & $7(25 \%)$ & $3(19 \%)$ & $4(33 \%)$ \\
\hline Hypertension & $6(21 \%)$ & $3(19 \%)$ & $3(25 \%)$ \\
\hline $\begin{array}{l}\text { Coronary } \\
\text { artery } \\
\text { disease }\end{array}$ & $3(11 \%)$ & $1(6 \%)$ & $2(16 \%)$ \\
\hline Diabetes & $3(11 \%)$ & $2(12 \%)$ & $1(8 \%)$ \\
\hline Weight (lbs) & $202 \pm 44.5$ & $173.7 \pm 31.4$ & $239.6 \pm 28.6^{*}$ \\
\hline Weight (kg) & $91.8 \pm 20.4$ & $78.8 \pm 14.3$ & $108.7 \pm 13.0^{*}$ \\
\hline Height (in) & $68.5 \pm 4.5$ & $68.4 \pm 3.9$ & $68.4 \pm 5.4$ \\
\hline BMI $\left(\mathrm{kg} / \mathrm{m}^{2}\right)$ & $30.33 \pm 6.54$ & $26.0 \pm 3.3$ & $36.2 \pm 5.0^{*}$ \\
\hline Age (years) & $49.5 \pm 11.5$ & $47.5 \pm 11.2$ & $52.1 \pm 11.7$ \\
\hline $\begin{array}{l}\text { LV ejection } \\
\text { fraction }(\%)\end{array}$ & $53.8 \pm 8.1$ & $56.3 \pm 6.2$ & $50.5 \pm 9.4$ \\
\hline $\begin{array}{l}\text { LV stroke } \\
\text { volume } \\
(\mathrm{ml})\end{array}$ & $70.5 \pm 16.4$ & $69.6 \pm 16.2$ & $71.6 \pm 17.4$ \\
\hline LV mass (g) & $133.6 \pm 45.0$ & $119.9 \pm 38.0$ & $151.8 \pm 48.6$ \\
\hline
\end{tabular}

$* p<0.05$ obese vs. non-obese

complete assessment of both agents in one imaging session. Care was taken to completely flush any residual adenosine from the tubing immediately after the first stress acquisition so that there was no contamination during the regadenoson bolus.

A stack of short axis cine scans to obtain left ventricular (LV) ejection fraction, volume and mass were acquired between the two stress acquisitions. The cine acquisition used a steady state free precession sequence $(\mathrm{TR} / \mathrm{TE}=2-3.3 / 1.2-1.5 \mathrm{~ms}$, flip angle $=$ $44^{\circ}-50^{\circ}$, slice thickness $=7 \mathrm{~mm}$, spacing between slices $=1.4 \mathrm{~mm})$. For the perfusion acquisitions, a $5 \mathrm{cc} / \mathrm{s}$ injection of Gd-BOPTA (Multihance ${ }^{\mathrm{TM}}$ ) was given, with doses of $0.02,0.03$ and $0.03 \mathrm{mmol} / \mathrm{kg}$, for rest, adenosine stress, and regadenoson stress, respectively. All injections were followed with a saline flush of $25 \mathrm{ml}$ at $5 \mathrm{cc} / \mathrm{s}$. The contrast was injected $\sim 3 \mathrm{~min}$ after the start of the adenosine infusion, and $\sim 90 \mathrm{~s}$ after the regadenoson injection. For first pass perfusion imaging, a saturation recovery radial turboFLASH sequence [15-17] was used with 72 rays acquired after each saturation pulse. Scan parameters were $\mathrm{TR}=2.6 \mathrm{~ms}, \mathrm{TE}=1.14 \mathrm{~ms}$, flip angle $14^{\circ}$, $2.3 \times 2.3 \times 8 \mathrm{~mm}$ voxel size, $2-4$ slices acquired each heartbeat for approximately $1 \mathrm{~min}$. All of the perfusion images were acquired during shallow breathing. Image reconstruction was performed with previously described methods [16].

MRI data analysis

The stack of 8-10 short axis cine images were processed using Argus software (Siemens) to obtain LV ejection fraction, volumes and mass. The myocardial perfusion imaging data were processed using custom software [18] to register the time frames, to compensate for respiratory motion, and then to segment the myocardium. In each slice, myocardial uptake time curves from six tissue regions equally spaced over $360^{\circ}$ were obtained. The slope of the rising phase of the intensity-time curve in the myocardium was calculated after using the acquisition timestamp in each frame for interpolation to uniformly spaced $0.5 \mathrm{~s}$ time frames. The maximum upslope over nine frames $(4.5 \mathrm{~s})$ was calculated for each region. This provides the most direct comparison of the two injections if it is assumed that the arterial input functions are similar. This type of analysis is relatively widely used [19].

To measure absolute myocardial perfusion, a region of interest in the LV blood pool was selected. An unsaturated arterial input function, which is necessary for quantitation, was obtained using the multiple saturation recovery time methods described by Kim

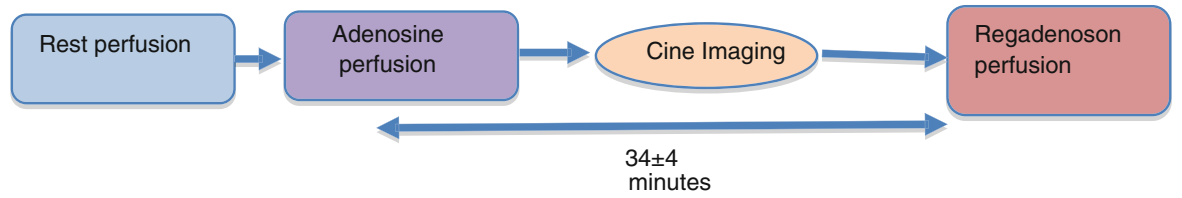

Fig. 1 Timeline of protocol. Resting perfusion was performed first with a dose of $0.02 \mathrm{mmol} / \mathrm{kg}$, followed by adenosine perfusion $(0.03 \mathrm{mmol} / \mathrm{kg}$ contrast agent injected after $3 \mathrm{~min}$ of infusion). Then a set of cine images were acquired, and after a waiting period regadenoson perfusion $(0.03 \mathrm{mmol} / \mathrm{kg}$ injected $\sim 90 \mathrm{~s}$ after the injection of regadenoson) was performed 
et al. [17]. The same myocardial uptake time curves described above for the upslope analysis were then fit with a compartment model to obtain values for myocardial perfusion. The perfusion values were reported as $\mathrm{ml} / \mathrm{min} / \mathrm{g}$ with the assumption that the specific gravity of the myocardial tissue was equal to $1 \mathrm{~g} / \mathrm{ml}$. Previous work has shown that the perfusion estimates with a compartment model and with modelindependent methods are not significantly different [20].

Examples of first pass MRI perfusion images and time intensity curves for each region are shown in Fig. 2. Myocardial perfusion reserve (MPR) was calculated as the ratio of myocardial blood flow during adenosine or regadenoson stress divided by the flow at rest. The analysis was repeated after normalizing resting perfusion values for resting rate-pressure product [21].

The subjects were divided into nonobese $(\mathrm{BMI} \leq$ $30 \mathrm{~kg} / \mathrm{m}^{2}$ ) and obese (BMI $>30 \mathrm{~kg} / \mathrm{m}^{2}$ ) groups, and the MPRs in the two groups for both vasodilators were compared. Regadenoson perfusion values were also normalized (divided) by adenosine perfusion values to better study if the ratio changed between the two groups with different BMIs.

Statistical analysis

A paired student's $t$ test was used to compare means of continuous values such as the MPRs obtained with adenosine and regadenoson. An unpaired $t$-test was used to compare the groups with different BMI's. Linear regression analysis was used to assess the correlation of the MPR values derived with each pharmacological agent and to determine whether BMI was related to MPR. Bland-Altman repeatability coefficient was calculated to assess systemic over or underestimation by one of the methods.

\section{Results}

Results were not obtained in two of the 30 subjects, both male, due to technical reasons. In one of the subjects the gadolinium contrast agent was not administered correctly. In another subject, the ECG gating signal was abruptly lost during the final perfusion scan.

The mean age of the study population was $49 \pm 11$ and mean BMI was $30.3 \pm 6.5$, range 19.6-46.6 (Table 1). Forty three $\%$ of the subjects were obese based on World Health Organization Criteria. Twenty five $\%$ of the subjects had a history of smoking, $21 \%$ had a history of hypertension, $11 \%$ patients had a history of diabetes and $11 \%$ had known CAD (Table 1). On the average, the subjects had normal LV systolic function, volume and mass (Table 1). Obese patients tended to have larger LV mass and stroke volumes compared to non-obese but the differences were not significant.
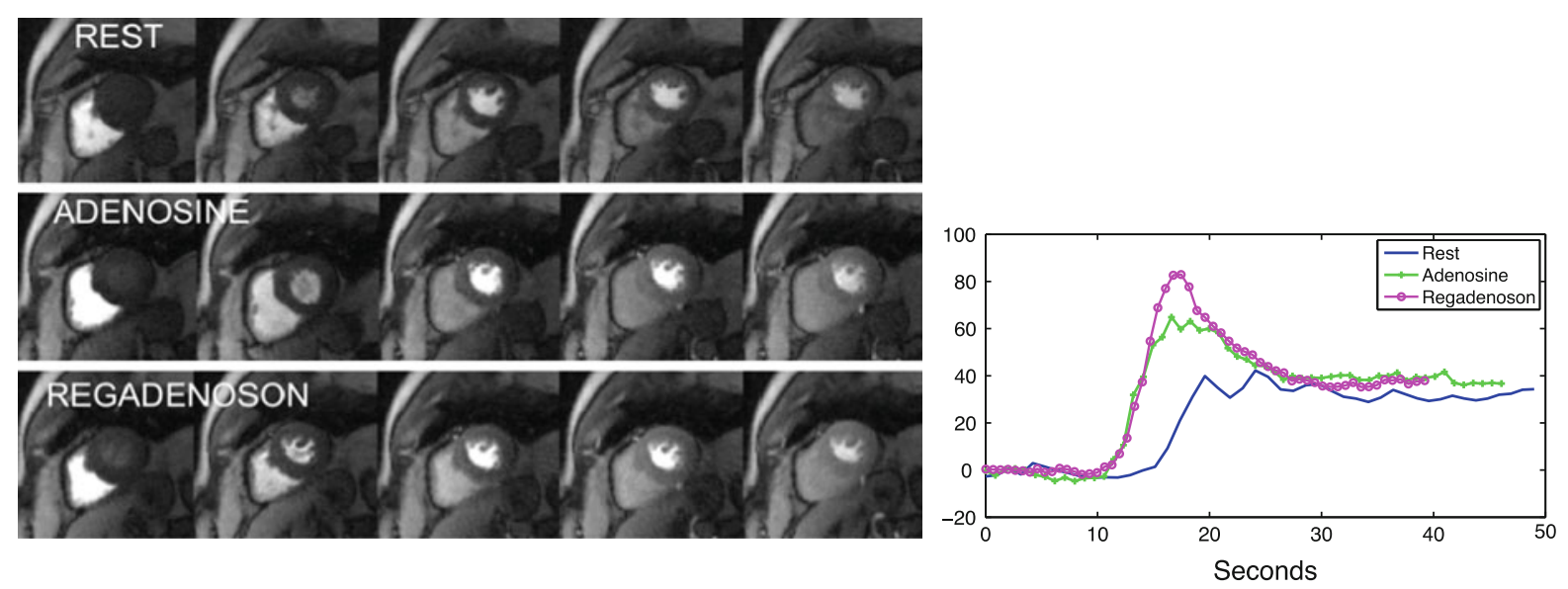

Fig. 2 Example of 2D radial pulse sequence, acquired at 3T. Left side Every third time frame shown of part of the cardiac perfusion radial (72 ray) acquisitions at rest or under vasodilation. The two vasodilators give similar images. Right side Example tissue uptake curves during rest, adenosine and regadenoson. The regadenoson peak appears higher in this particular example, although the upslopes are similar. For the entire population, the upslopes and peak tissue values were comparable with adenosine and regadenoson stress 
Table 2 Hemodynamic responses to adenosine and regadenoson

\begin{tabular}{lccc}
\hline & All subjects & Nonobese $\left(\mathrm{BMI} \leq 30 \mathrm{~kg} / \mathrm{m}^{2}\right)$ & Obese $\left(\mathrm{BMI}>30 \mathrm{~kg} / \mathrm{m}^{2}\right)$ \\
\hline Resting heart rate $(\mathrm{bpm})$ & $68 \pm 11$ & $65 \pm 8$ & $71 \pm 14$ \\
Resting systolic blood pressure $(\mathrm{mmHg})$ & $143 \pm 20$ & $138 \pm 20$ & $151 \pm 19$ \\
Resting rate-pressure product $(\mathrm{bpm} * \mathrm{mmHg})$ & $9763 \pm 2332$ & $8997 \pm 1705$ & $10785 \pm 2717^{*}$ \\
Heart rate adenosine $(\mathrm{bpm})$ & $93 \pm 20$ & $88 \pm 18$ & $100 \pm 21$ \\
Heart rate regadenoson $(\mathrm{bpm})$ & $95 \pm 17$ & $93 \pm 16$ & $99 \pm 19$ \\
\hline
\end{tabular}

$* p<0.05$ obese vs. non-obese

Hemodynamic responses to adenosine and regadenoson

Resting heart rate, blood pressure (BP) and ratepressure product for the entire group and those with BMI $\leq 30 \mathrm{~kg} / \mathrm{m}^{2}$ or $>30 \mathrm{~kg} / \mathrm{m}^{2}$ are shown in Table 2 . There were no difference in the hemodynamic responses to adenosine and regadenoson for the overall group. Non-obese and obese subjects also responded similarly. Heart rate tended to increase more in obese versus nonobese subjects with both agents, but only resting rate-pressure product was significantly greater for the obese subjects. Heart rate increased significantly by a mean of $\sim 37 \%$ from rest to stress with both adenosine and regadenoson. There were no serious adverse events. Nineteen of the subjects felt regadenoson produced fewer side effects, five preferred adenosine and four felt they were equivalent.

Comparison of MPR derived with regadenoson and adenosine

There was a close correlation between the upslopes of the myocardial tissue time-intensity curves obtained with adenosine and regadenoson (Fig. 3). Absolute myocardial blood flows at rest and with each stress agent are shown in Table 3. There were no statistical differences between the maximal blood flows obtained with adenosine and regadenoson. There was a moderately strong correlation $(r=0.72$, regadenoson MPR $=1.11 *($ adenosine $\mathrm{MPR})-0.06)$ between MPR derived during administration of fixed dose regadenoson and weight-adjusted adenosine (Fig. 4). The 95\% confidence interval of the difference in MPRs was [ -0.44 to 0.06]. With the sample size of 28 subjects imaged here, differences in mean MPR of at least 0.4 would be detected $90 \%$ of the time. The Bland-Altman analysis reflects an $8 \%$ lower adenosine mean MPR compared to regadenoson MPR, though no systematic trends of MPR with either agent were observed (Fig. 5). The coefficient of repeatability between the two measures of MPR was 1.26. Normalization of myocardial blood flow based on resting rate-pressure product increased the MPR for both adenosine and regadenoson, although the corrected MPRs were not significantly different between the two BMI groups (Table 3).

Effect of body mass index on MPR with each vasodilator

There was a mild negative association between MPR and BMI as assessed with both vasodilators, i.e., MPR tended to be lower as the severity of obesity increased

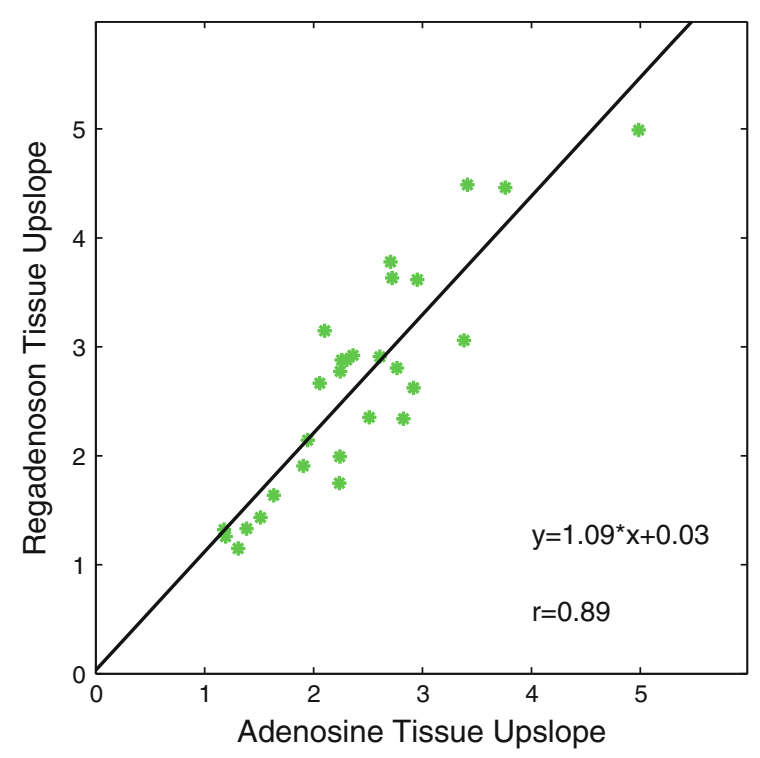

Fig. 3 Correlation between mean tissue curve upslopes in each patient during adenosine and regadenoson. The upslopes correlate closely 
Table 3 Comparison of Myocardial Perfusion Reserve (MPR) obtained with adenosine or regadenoson

\begin{tabular}{llll}
\hline & All subjects & BMI $\leq 30 \mathrm{~kg} / \mathrm{m}^{2}$ & BMI $>30 \mathrm{~kg} / \mathrm{m}^{2}$ \\
\hline Myocardial blood flow rest $(\mathrm{ml} / \mathrm{min} / \mathrm{g})$ & $0.70 \pm 0.16$ & $0.69 \pm 0.14$ & $0.72 \pm 0.20$ \\
Myocardial blood flow adenosine $(\mathrm{ml} / \mathrm{min} / \mathrm{g})$ & $1.49 \pm 0.43$ & $1.53 \pm 0.43$ & $1.42 \pm 0.44$ \\
Myocardial blood flow regadenoson $(\mathrm{ml} / \mathrm{min} / \mathrm{g})$ & $1.61 \pm 0.65$ & $1.74 \pm 0.57$ & $1.44 \pm 0.73$ \\
Myocardial perfusion reserve adenosine & $2.25 \pm 0.59$ & $2.37 \pm 0.59$ & $2.09 \pm .58$ \\
Myocardial perfusion reserve regadenoson & $2.44 \pm 0.92$ & $2.67 \pm 1.18$ & $2.06 \pm 0.89$ \\
Myocardial perfusion reserve adenosine, normalized to resting RPP & $2.41 \pm 1.09$ & $2.68 \pm 0.97$ & $2.15 \pm 0.74$ \\
Myocardial perfusion reserve regadenoson, normalized to resting RPP & $2.44 \pm 1.19$ & $2.81 \pm 1.18$ & $1.95 \pm 1.05$ \\
Ratio of MPR with regadenoson to MPR with adenosine & $1.08 \pm 0.26$ & $1.15 \pm 0.23$ & $1.0 \pm 0.28$ \\
\hline
\end{tabular}

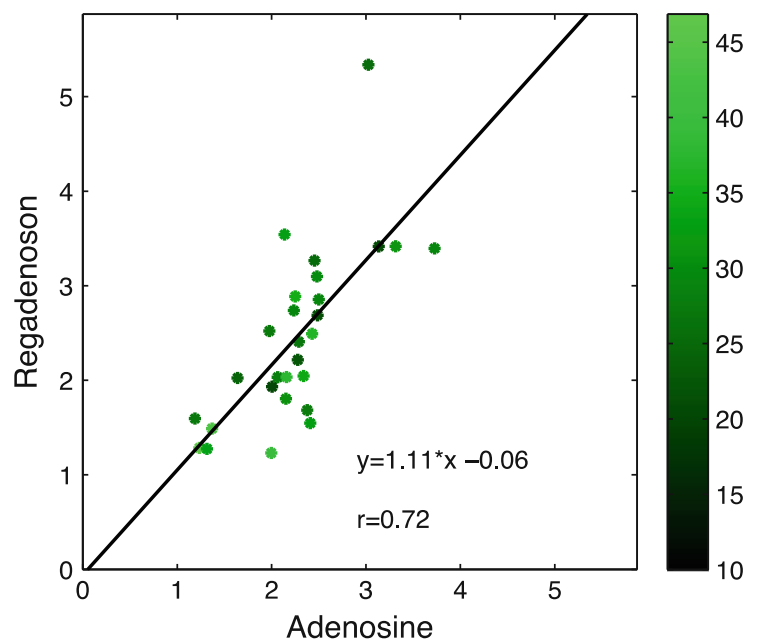

Fig. 4 Correlation between mean myocardial perfusion reserve (MPR) in each subject measured with adenosine and regadenoson. The color bar codes the subjects by BMI

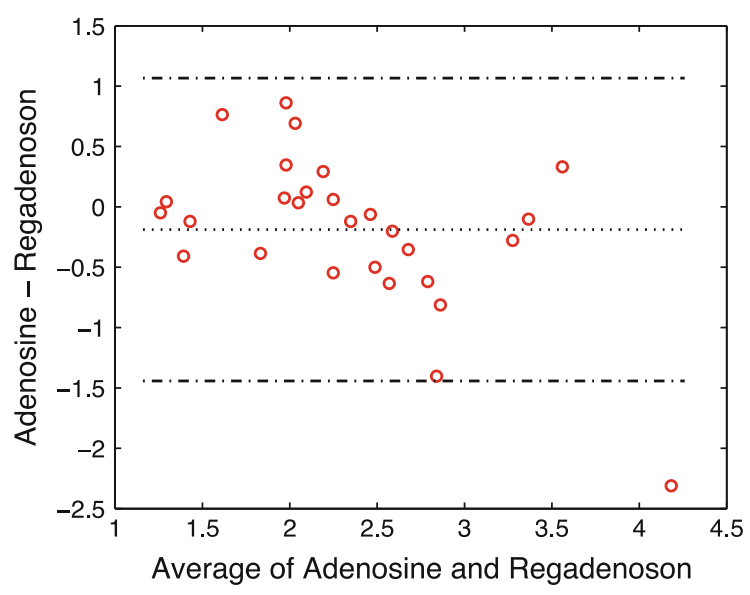

Fig. 5 Bland-Altman plot showing showing a small negative bias for the difference of mean MPR with adenosine or regadenoson $(\mathrm{r}=-0.37$ with adenosine and $\mathrm{r}=-0.4$ with regadenoson, Fig. 6). The ratio of MPR obtained with regadenoson to that obtained with adenosine was higher in the low BMI group than in the high BMI group, but was not significantly different between the two BMI groups (Table 3). In other words, fixed dose regadenoson tended to produce higher MPR than adenosine in nonobese subjects. However, a similar trend was not seen in the obese group.

\section{Discussion}

The main finding of this study was that the values for MPR measured with regadenoson did not differ significantly from those obtained with weight-adjusted adenosine infusion, even when including subjects with widely varying body weight and adiposity. The use of regadenoson substantially simplifies the protocol for MR perfusion imaging compared to the protocol used for adenosine studies since regadenoson does not require calculation of the dose, requires only one intravenous access and a specially designed infusion pump for use in the magnet is not necessary.

\section{Comparison with prior studies}

Gordi et al. [5] reported data regarding the use of a single dose of regadenoson in all patients. These authors studied 36 relatively thin subjects (mean BMI $=24.4 \pm 3.0$ ). The study endpoints were plasma levels of the drug and hemodynamic measurements. Their findings supported the use of a fixed dose of regadenoson. Another study used invasively measured coronary flow velocities as the main outcome measure. These authors showed that a smaller dose of 
Fig. 6 Correlation between MPR and BMI during a adenosine and b regadenoson. With both drugs, there is a mild inverse relationship between MPR and BMI suggesting that MPR decreases as the severity of obesity increases
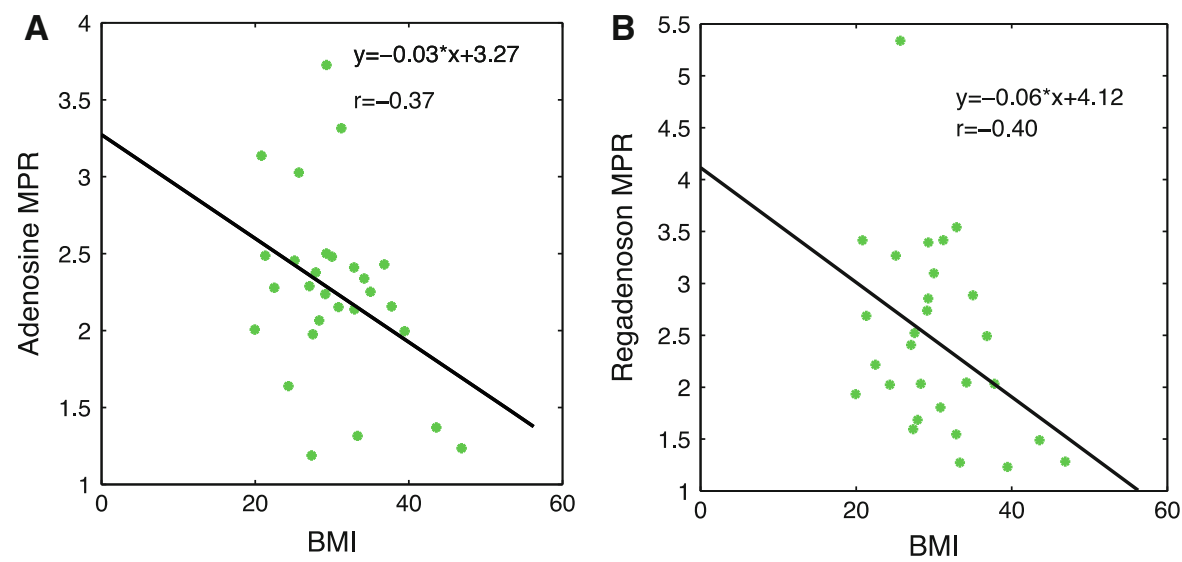

regadenoson $(100 \mu \mathrm{g})$ provided coronary flow increases similar to that from $400 \mu \mathrm{g}$ (the dose that is used clinically). However, coronary hyperemia lasted for a shorter time with the lower dose [11]. The ADVANCE 3 study evaluated large numbers of patients who underwent sequential SPECT studies on different days with adenosine and regadenoson [11]. This study found good agreement in the assessment of ischemia detected with SPECT performed during adenosine- or regadenoson-induced coronary vasodilation. Agreement between the two agents was considered to be "good" because it was similar to the agreement rate between sequential adenosine scans $(0.62 \pm 0.03)[10]$. Patients in the ADVANCE 3 study were older than in the current study, with a mean age of 64. Average weight in ADVANCE 3 was $82 \pm 8 \mathrm{~kg}$ with BMI $29 \pm 5$. The ADVANCE study has also been analyzed to determine if patients with a larger BMI had similar agreement with adenosine. The patients were divided into those with $\mathrm{BMI} \leq 30$ $(\mathrm{n}=770)$ and those with BMI $>30(\mathrm{n}=470)$. In that analysis, no significant difference in diagnostic agreement with adenosine was found [10]. That work also reported that regadenoson agreed with adenosine for detection of reversible myocardial defects across age (above or below age 65), across gender and in diabetics. Further analysis of portions of the ADVANCE data set with regard to BMI and plasma regadenoson concentrations also reported diagnostic SPECT imaging efficacy at high BMI, and found that even at high BMI, plasma concentrations were above the $12 \mathrm{ng} / \mathrm{ml}$ threshold thought sufficient for vasodilator for imaging [22].

In our study, both vasodilators showed a trend for reduced MPR in larger BMI patients. A similar effect has been reported previously with dipyridamole and quantitative PET, where in a low risk population it was found that stress hyperemia was approximately $13 \%$ less in an obese group than in controls [23]. In the current study, there was a tendency for MPR measured with regadenoson to be higher than that measured with adenosine in low BMI subjects and to decrease more as BMI increased (Table 3; Fig. 6). However, the differences between the normal and high BMI groups were not significantly different. More study of how obesity affects coronary reactivity is needed for all vasodilators since some reports suggest that up to $20 \%$ of dipyridamole and $8 \%$ of adenosine infusions do not produce maximal coronary hyperemia [24]. The design of new imaging strategies and testing protocols will increasingly need to account for the effects of obesity.

It is of interest to consider how the correspondence of MPR measured with adenosine and regadenoson compare to previous works studying repeated adenosine scans. Using ${ }^{15} \mathrm{O}$-labeled water and dynamic PET, the coefficient of repeatability (two standard deviations of the difference) in the same healthy subjects approximately 20 min apart was 1.3 (33\% of the mean MPR) [25]. Previous work with repeatability of MRI adenosine perfusion reported $\mathrm{r}=0.7$ for global MPR measured on different days. That study had a repeatability coefficient of 1.5 (53\% of the mean MPR) [26]. Studies performed further apart in time $(\sim 1$ year) had a coefficient of repeatability of 1.13 at hyperemia (41\% of mean), although MPR correspondence was not reported [27]. In the current study, we found a correlation with $\mathrm{r}=0.7$ between regadenoson and adenosine, and a coefficient of repeatability between the two measures of MPR of 1.26 (54\% of the mean MPR), which is similar to the repeated adenosine studies. 
Previous quantitative MRI perfusion studies have reported wide ranges of MPR from 2.1 to 4.2 [20]. Most of the studies were in normal volunteers. The flow reserves in the current study are in the lower end of this reported range. Other studies have reported similar MPR values to those we obtained. For example, Fritz Hansen et al. measured MPR $=2.4 \pm 0.8$ measured with MRI in 10 healthy males [28]. Likewise, Ishimori et al. [19] reported MPR of 2.4 and 2.1 in the subepicardium and subendocardium of normal female subjects. Goudarzi et al. [29] performed quantitative ${ }^{82} \mathrm{Rb}$ PET on 52 subjects with regadenoson and reported an MPR $=2.9 \pm 0.8$. The MPR agreed with that calculated in a similar population when dipyridamole was used $(2.8 \pm 0.7)$. The subjects in our current study were middle aged, had a moderate number of cardiac risk factors and $11 \%$ had known coronary artery disease, all of which could have contributed to reduced MPRs compared to those in younger and healthier populations. The inclusion of subjects with varying clinical characteristics, including known CAD, was not an issue for our study since we performed direct (paired) comparison of adenosine and regadenoson in each subject in the same imaging session.

\section{Timing of injections}

Imaging was started approximately $90 \mathrm{~s}$ after injection of regadenoson. This timing differs from the standard regadenoson SPECT protocol in which tracer is injected $\sim 20 \mathrm{~s}$ after regadenoson administration. The timing for our protocol was chosen because of differences between MRI and SPECT perfusion imaging. The optimal timing of tracer administration during SPECT imaging depends on the extraction properties of the specific tracer being used. Data obtained with a Doppler flow wire showed that maximal blood velocity occurred in the coronary artery from approximately $60-140 \mathrm{~s}$ after bolus injection of regadenoson [7]. This finding and the preference to acquire MRI data while the heart rate was relatively steady resulted in the selection of gadolinium injection at $\sim 90 \mathrm{~s}$ after regadenoson. Recent work by others has also concluded that approximately $90 \mathrm{~s}$ gives optimal injection timing for MRI perfusion studies, based on MRI measurements of flow in the coronary sinus [7].
Regadenoson elevates heart rate and myocardial perfusion for a longer time period than does adenosine. Some data show that $45 \mathrm{~min}$ may be required for heart rate to return to baseline after a bolus of regadenoson [11]. In our study, we observed that heart rate had typically returned to approximately baseline by $15 \mathrm{~min}$ in most patients. The longer duration of elevated heart rate after receiving regadenoson versus adenosine may hinder the use of some imaging sequences after the administration of regadenoson. For this reason, it may be advisable to perform rest perfusion first (possibly with a lower dose of gadolinium), followed by cine imaging of LV function to allow washout of gadolinium, followed by stress imaging and finally delayed enhancement. Alternatively, stress-only studies have been advocated for adenosine, and might suit regadenoson well [30, 31].

Study limitations

There are several technical factors that could affect the interpretation of our data. Adenosine was given first each time, and this may have influenced how the subjects rated the tolerability of the agents. As well, since more contrast had been given by the time the regadenoson was used, this could have affected the time curves obtained during the final data acquisitions. However, since relatively low doses of contrast agent were used and there was at least 30 min between the two stress perfusion measurements, this effect is likely small. The method used to obtain an accurate arterial input function has been validated at rest with $0.02 \mathrm{mmol} / \mathrm{kg}$ doses of GdBOPTA, which were shown to have significant (0-70\% saturation) saturation at the peak [17]. It is possible that the method does not work as well with the $0.03 \mathrm{mmol} / \mathrm{kg}$ doses used in the stress injections here. However, identical processing was applied to both adenosine and regadenoson images so that even if the method did not correct for all saturation, the comparisons should still be valid. Semi-quantitative tissue upslope results were also reported to confirm the similarity of uptake in the myocardial tissue during each drug, without any influence from the AIF calculations.

The major limitation of this study is the relatively small sample size. The intent was not to prove the diagnostic accuracy of regadenoson in the evaluation of patients with possible coronary artery 
disease. Rather, the goal was to demonstrate whether a single fixed size dose of regadenoson produces comparable coronary hyperemia across the range of body sizes seen in a clinical setting, and to explore the suitability of regadenoson for use during MRI. Larger studies are needed to assess the diagnostic performance of this particular pharmacological stress agent and imaging modality. For this purpose, multi-center trials comparing regadenoson and other vasodilators will be needed. While the large corpus of work with SPECT imaging implies that regadenoson will likely be equivalent to adenosine, the different protocols involved with MRI and the different imaging processes makes this critical to test. In addition, since hyperemic blood flow is at a steady state for a relatively brief period after administration of regadenoson, further testing regarding the reproducibility for quantitative studies is important.

\section{Conclusions}

Regadenoson is safe, well tolerated and time efficient as a pharmacological vasodilator for cardiac stress perfusion MRI studies. Only one intravenous access is required and there is no need for a specialized, magnet-safe infusion pump. Myocardial perfusion reserve measured during administration of fixed-dose, bolus administration of regadenoson is comparable to that obtained with adenosine across a range of patient sizes. Simplification of the stress protocol may make MR an increasingly attractive modality for the diagnostic assessment of subjects with known or suspected CAD. A multi-center trial to determine the performance of regadenoson as a stress agent in cardiac MRI seems warranted.

Acknowledgments The authors express their appreciation to Mr. Henry Buswell, Mr. Josh Bertola and Ms. Melody Johnson for their invaluable assistance with data collection. This study was supported by a research grant from Astellas Pharma to Dr. Litwin and Dr. DiBella and NIH R01EB000177 to Dr. DiBella.

Conflict of interest Research funding from Astellas Pharma.

Open Access This article is distributed under the terms of the Creative Commons Attribution Noncommercial License which permits any noncommercial use, distribution, and reproduction in any medium, provided the original author(s) and source are credited.

\section{References}

1. Poirier P, Giles TD, Bray GA, Hong Y, Stern JS, Pi-Sunyer FX, Eckel RH (2006) Obesity and cardiovascular disease: pathophysiology, evaluation, and effect of weight loss: an update of the 1997 American Heart Association scientific statement on obesity and heart disease from the obesity committee of the council on nutrition, physical activity, and metabolism. Circulation 113:898-918

2. Madala MC, Franklin BA, Chen AY, Berman AD, Roe MT, Peterson ED, Ohman EM, Smith SC Jr, Gibler WB, McCullough PA (2008) Obesity and age of first non-stsegment elevation myocardial infarction. J Am Coll Cardiol 52:979-985

3. Al Jaroudi W, Iskandrian AE (2009) Regadenoson: a new myocardial stress agent. J Am Coll Cardiol 54:1123-1130

4. Gordi T, Blackburn B, Lieu H (2007) Regadenoson pharmacokinetics and tolerability in subjects with impaired renal function. J Clin Pharmacol 47:825-833

5. Gordi T, Frohna P, Sun HL, Wolff A, Belardinelli L, Lieu H (2006) A population pharmacokinetic/pharmacodynamic analysis of regadenoson, an adenosine $\mathrm{A}_{2 \mathrm{~A}}$-receptor agonist, in healthy male volunteers. Clin Pharmacokinet 45: 1201-1212

6. Hage FG, Heo J, Franks B, Belardinelli L, Blackburn B, Wang W, Iskandrian AE (2009) Differences in heart rate response to adenosine and regadenoson in patients with and without diabetes mellitus. Am Heart J 157:771-776

7. Booker OJ, Bandettini P, Kellman P, Wilson J, Leung S, Vasu S, Shanbhag S, Henry J, Lowrey T, Mancini C, Arai AE (2011) Time resolved measure of coronary sinus flow following regadenoson administration. J Cardiovasc Magn Reson 13(Suppl 1):O74

8. Watkins S, McGeoch R, Lyne J, Steedman T, Good R, McLaughlin MJ, Cunningham T, Bezlyak V, Ford I, Dargie HJ, Oldroyd KG (2009) Validation of magnetic resonance myocardial perfusion imaging with fractional flow reserve for the detection of significant coronary heart disease. Circulation 120:2207-2213

9. Schwitter J, Wacker CM, van Rossum AC, Lombardi M, AlSaadi N, Ahlstrom H, Dill T, Larsson HB, Flamm SD, Marquardt M, Johansson L (2008) MR-IMPACT: Comparison of perfusion-cardiac magnetic resonance with single-photon emission computed tomography for the detection of coronary artery disease in a multicentre, multivendor, randomized trial. Eur Heart J 29:480-489

10. Cerqueira MD, Nguyen P, Staehr P, Underwood SR, Iskandrian AE (2008) Effects of age, gender, obesity, and diabetes on the efficacy and safety of the selective $\mathrm{A}_{2 \mathrm{~A}}$ agonist regadenoson versus adenosine in myocardial perfusion imaging integrated ADVANCE-MPI trial results. JACC Cardiovasc Imaging 1:307-316

11. Iskandrian AE, Bateman TM, Belardinelli L, Blackburn B, Cerqueira MD, Hendel RC, Lieu H, Mahmarian JJ, Olmsted A, Underwood SR, Vitola J, Wang W (2007) Adenosine versus regadenoson comparative evaluation in myocardial perfusion imaging: Results of the ADVANCE phase 3 multicenter international trial. J Nucl Cardiol 14:645-658

12. Thomas GS, Tammelin BR, Schiffman GL, Marquez R, Rice DL, Milikien D, Mathur V (2008) Safety of 
regadenoson, a selective adenosine $\mathrm{A}_{2 \mathrm{~A}}$ agonist, in patients with chronic obstructive pulmonary disease: a randomized, double-blind, placebo-controlled trial (regcopd trial). J Nucl Cardiol 15:319-328

13. Leaker BR, O'Connor B, Hansel TT, Barnes PJ, Meng L, Mathur VS, Lieu HD (2008) Safety of regadenoson, an adenosine $\mathrm{A}_{2 \mathrm{~A}}$ receptor agonist for myocardial perfusion imaging, in mild asthma and moderate asthma patients: a randomized, double-blind, placebo-controlled trial. J Nucl Cardiol 15:329-336

14. Zhao G, Messina E, Xu X, Ochoa M, Sun HL, Leung K, Shryock J, Belardinelli L, Hintze TH (2007) Caffeine attenuates the duration of coronary vasodilation and changes in hemodynamics induced by regadenoson (cvt-3146), a novel adenosine $\mathrm{A}_{2 \mathrm{~A}}$ receptor agonist. J Cardiovasc Pharmacol 49:369-375

15. Kholmovski EG, DiBella EVR (2007) Perfusion MRI with radial acquisition for arterial input function assessment. Magn Reson Med 57:821-827

16. Adluru G, McGann C, Speier P, Kholmovski EG, Shaaban A, DiBella EV (2009) Acquisition and reconstruction of undersampled radial data for myocardial perfusion magnetic resonance imaging. J Magn Reson Imaging 29: 466-473

17. Kim TH, Pack NA, Chen L, DiBella EVR (2010) Quantification of myocardial perfusion using $\mathrm{cmr}$ with a radial data acquisition: comparison with a dual-bolus method. J Cardiovasc Magn Reson 12:45

18. Pack N, Vijayakumar S, Kim TH, McGann C, DiBella E (2009) A semi-automatic software package for analysis of dynamic contrast-enhanced MRI myocardial perfusion studies. Comput Cardiol 36:269-272. http://www.cinc.mit. edu/archives/2009/pdf/0269.pdf

19. Ishimori ML, Martin R, Berman DS, Goykhman P, Shaw LJ, Shufelt C, Slomka PJ, Thomson LE, Schapira J, Yang Y, Wallace DJ, Weisman MH, Bairey Merz CN (2011) Myocardial ischemia in the absence of obstructive coronary artery disease in systemic lupus erythematosus. JACC Cardiovasc Imaging 4:27-33

20. Pack N, DiBella EVR (2010) Comparison of myocardial blood flow estimates from dynamic contrast-enhanced magnetic resonance imaging with four quantitative analysis methods. Magn Reson Med 64:125-137

21. Czernin J, Muller P, Chan S, Brunken RC, Porenta G, Krivokapich J, Chen K, Chan A, Phelps ME, Schelbert HR (1993) Influence of age and hemodynamics on myocardial blood flow and flow reserve. Circulation 88:62-69

22. Reyes E, Staehr P, Olmsted A, Zeng D, Blackburn B, Cerqueira MD, Underwood SR (2011) Effect of body mass index on the efficacy, side effect profile, and plasma concentration of fixed-dose regadenoson for myocardial perfusion imaging. J Nucl Cardiol 18:620-627

23. Schindler TH, Cardenas J, Prior JO, Facta AD, Kreissl MC, Zhang XL, Sayre J, Dahlbom M, Licinio J, Schelbert HR (2006) Relationship between increasing body weight, insulin resistance, inflammation, adipocytokine leptin, and coronary circulatory function. J Am Coll Cardiol 47:1188-1195

24. Iskandrian AE (1998) State of the art for pharmacologic stress imaging. In: Zaret BL, Beller GA (eds) Nuclear cardiology: state of the art and future directions. Mosby-Year Book, New York, pp 312-330

25. Kaufmann PA, Gnecchi-Ruscone T, Yap JT, Rimoldi O, Camici PG (1999) Assessment of the reproducibility of baseline and hyperemic myocardial blood flow measurements with (15)O-labeled water and PET. J Nucl Med 40: 1848-1856

26. Elkington AG, Gatehouse PD, Ablitt NA, Yang G-Z, Firmin DN, Pennell DJ (2005) Interstudy reproducibility of quantitative perfusion cardiovascular magnetic resonance. J Cardiovasc Magn Reson 7:815-822

27. Jerosch-Herold M, Vazquez G, Wang L, Jacobs DR Jr, Folsom AR (2008) Variability of myocardial blood flow measurements by magnetic resonance imaging in the multiethnic study of atherosclerosis. Invest Radiol 43:155-161

28. Fritz-Hansen T, Hove JD, Kofoed KF, Kelbaek H, Larsson HB (2008) Quantification of MRI measured myocardial perfusion reserve in healthy humans: a comparison with positron emission tomography. J Magn Reson Imaging 27:818-824

29. Goudarzi B, Fukushima K, Bravo P, Merrill J, Bengel FM (2011) Comparison of the myocardial blood flow response to regadenoson and dipyridamole: a quantitative analysis in patients referred for clinical (82)Rb myocardial perfusion PET. Eur J Nucl Med Mol Imaging 38:1908-1916

30. Giang TH, Nanz D, Coulden R, Friedrich M, Graves M, AlSaadi N, Luscher TF, von Schulthess GK, Schwitter J (2004) Detection of coronary artery disease by magnetic resonance myocardial perfusion imaging with various contrast medium doses: first European multi-centre experience. Eur Heart J 25:1657-1665

31. Cury RC, Cattani CA, Gabure LA, Racy DJ, de Gois JM, Siebert U, Lima SS, Brady TJ (2006) Diagnostic performance of stress perfusion and delayed-enhancement $\mathrm{mr}$ imaging in patients with coronary artery disease. Radiology 240:39-45 